\title{
Accuracy instructions differently modulate visual and non-visual contributions to ongoing reaches
}

\author{
John de Grosbois, Kimberley Jovanov, and \\ Luc Tremblay
}

Version Post-print/accepted manuscript

Citation de Grosbois, J., Jovanov, K., \& Tremblay, L. (2019). Accuracy

(published version) instructions differently modulate both visual and non-visual

contributions to ongoing reaches. Canadian Journal of Experimental

Psychology. DOI:10.1037/cep0000162

\section{How to cite TSpace items}

Always cite the published version, so the author(s) will receive recognition through services that track citation counts, e.g. Scopus. If you need to cite the page number of the author manuscript from TSpace because you cannot access the published version, then cite the TSpace version in addition to the published version using the permanent URI (handle) found on the record page.

This article was made openly accessible by $U$ of $T$ Faculty.

Please tell us how this access benefits you. Your story matters. 
1 RUNNING HEAD: Accuracy instructions and online control

2

3

4

5

6 Accuracy instructions differently modulate visual and non-visual contributions to ongoing reaches

John de Grosbois ${ }^{1,2}$, Kimberley Jovanov ${ }^{1,2}$, Luc Tremblay ${ }^{1,2}$

$8 \quad{ }^{1}$ Faculty of Kinesiology and Physical Education, University of Toronto, Toronto, Ontario, Canada

${ }^{2}$ Centre for Motor Control, University of Toronto, Toronto, Ontario, Canada

10

Canada

11

12

13 Correspondence:

14 Dr. Luc Tremblay

15 University of Toronto

1655 Harbord St.

17 Toronto, Ontario, M5S 2W6, Canada.

18 luc.tremblay@utoronto.ca.

19

20

21

22 



\section{Abstract}

24 The control of ongoing goal-directed reaches is influenced by both visual and non-visual sensorimotor processes. Notably, intentions to produce accurate movements also influence reaching performance. However, it is not known whether these improvements associated with accuracy-based intentions can be attributed to changes in movement planning and / or online control. Notably, such improvements may come about via both visual and non-visual online control processes. Using frequency domain analyses, the relative online contributions of visual and non-visual sub-processes to reaching performance have been previously identified (e.g., de

31 Grosbois \& Tremblay, 2017; de Grosbois \& Tremblay, 2018). Thus, the current study tested if the 32 relative contributions of these online control sub-processes are influenced by instructions to be accurate. Reaching movements were completed in the presence of three experimental manipulations. First, vision during voluntary reaches was either provided or occluded. Second, high- and low-accuracy instruction sets were provided. And third, the predictability of visual information was manipulated through blocked and randomized feedback scheduling. The results

37 indicated that the contribution of online visuomotor processes (i.e., visual sub-process) was 38 increased by the availability of online vision and instructions to be accurate. In contrast, the non39 visual sub-process was promoted in the absence of online vision, but suppressed when a randomized feedback schedule was implemented with instructions to be accurate. Ultimately,

41 instructions to be accurate increase the relative contribution of vision-based online sensorimotor 42 processes and can decrease the contributions of non-visual online sensorimotor processes.

43 Keywords: online control; accuracy instructions; intentions; vision; proprioception 
44 Public Significance Statement:

45 The current study examined the use of sensory information during simple reaching movements.

46 More specifically, how efforts to produce accurate movements influence visual and non-visual

47 contributions to performance. Instructions to be accurate facilitated visual processing but

48 inhibited non-visual processing associated with reaches. 
Accuracy instructions differently modulate visual and non-visual contributions to ongoing reaches

As shown in the seminal contributions of Woodworth (1899), movements completed with

52 vision available (i.e., full-vision) are typically performed with greater levels of accuracy than

53 movements completed without the availability of online vision (i.e., no-vision). Equally

54 unsurprising was the additional finding that providing instructions to produce accurate movements led to improvements in endpoint accuracy. Inherently, these performance changes could stem from changes in movement planning and / or online feedback utilization (i.e., online control). Thus, the current study sought to evaluate the influence of instructions to be accurate on the contributions of online control processes.

60 Bowden, 1971; Meyer, Abrams, Kornblum, Wright, \& Smith, 1988; see Elliott, Helsen, \& Chua,

612001 for a review) have developed hand-in-hand with advancements in the techniques associated

62 with the quantification of movement performance. For example, earlier work (e.g., Fitts, 1954;

63 Keele \& Posner, 1968) quantified movement accuracy solely based on target hits and misses. A

64 presumption was that feedback acted as a servomechanism (e.g., Craik, 1947) and that the

65 utilization of feedback would result in relatively more target hits. The invention of motion

66 tracking systems led to the quantification of movement accuracy in terms of the spatial

67 variability of the movement endpoints (e.g., Zelaznik, Hawkins, \& Kisselburgh, 1983). The

68 evaluation of movement variability has since garnered insights into the complexities of online 
control as a multi-faceted construct (e.g., Tremblay, Hansen, Kennedy, \& Cheng, 2013).

In addition to the association between online feedback utilization and changes in endpoint performance, Woodworth (1899) also noted that movements completed with vision available exhibited more quantifiable discontinuities. Consequently, greater contributions of online feedback utilization came to be associated with the presence of movement discontinuities and researchers developed techniques for both their quantification (e.g., jerk score: see Tresilian, Stelmach, \& Adler, 1997) and their utility (e.g., index of error-correction effectiveness: see Khan, Franks, \& Goodman, 1998). However, it has since been demonstrated that a simple reliance on the incidence of discontinuities is unwarranted, given that neither the presence (e.g., Elliot, Carson, Goodman, \& Chua, 1991; Jeannerod, 1986; Poston et al., 2013), nor the absence (e.g., For example, Pélisson, Prablanc, Goodale, \& Jeannerod, 1986) of discontinuities can be strongly associated with changes in online feedback utilization.

Subsequently, Elliott et al. (1991) formalized the idea of feedback utilization in the absence of observable discrete corrections in what became known as the pseudocontinuous model of online control. In the pseudocontinuous model, corrective processes are completed in an iterative, overlapping fashion, which often results in a relatively smooth kinematic profile. Accordingly, methodologies based on movement variability across trials have been developed (i.e., multiple-trial measures). These methodologies have focused on either the magnitude of the variability at different points across the movements (i.e., Khan \& Franks, 2003; Khan et al., 2006; Hansen, Elliott, \& Khan, 2008) or correlations between position-based kinematic markers 
across multiple movements (i.e., Bernier, Chua, Franks, \& Khan, 2006; Elliott, Binsted, \& Heath, 1999; Heath, Westwood, \& Binsted, 2004; Messier, \& Kalaska, 1999). In general, significant decreases in variability across the movement and lower correlations have been associated with a relatively greater contribution of online control process. However, given the necessity of multiple trials within these types of measures, they are likely more sensitive to the contributions of offline, planning-related processes than within trial measures (e.g., de Grosbois \& Tremblay, 2018).

6

A novel, within-trial approach for quantifying iterative, pseudocontinuous corrective processes was developed by de Grosbois and Tremblay (2016). This approach utilized analyses in the frequency domain (i.e., pPower analysis). de Grosbois and Tremblay (2016) reasoned that a relatively stable visuomotor feedback time could be expected due to the convergence of two lines of research. First, the relative stability of corrective reaction times across a range of movement parameters (e.g., Cressman, Cameron, Lam, Franks, \& Chua, 2010; Saunders \& Knill, 2003; Veyrat-Masson, Brière, \& Proteau, 2010). And second, the overlap of these corrective reaction times with the minimum time with vision that is required to observe a change in reaching endpoint performance (e.g., Zelaznik et al., 1983). The contribution of this relatively stable visuomotor influence on reaching performance was isolated by fitting a smooth, $5^{\text {th }}$ order polynomial to the acceleration profile (i.e., a minimum jerk trajectory: see Flash \& Hogan, 1985) and evaluating the relative frequency power in the residuals ${ }^{1}$. It was asserted that these residuals

1 A $5^{\text {th }}$ order polynomial was chosen because of the four natural bends found within the 
Accuracy instructions and online control

108 would better contain information regarding the influences of online corrective processes (see also

109 Noy et al., 2015). Notably the frequencies at which differences between conditions were

110 observed could provide evidence for the underlying rates of the associated processes responsible

111 for the performance differences (see de Grosbois and Tremblay, 2016 for a more detailed

112 discussion). Using this methodology, increased relative power has been observed in the presence

113 relative to the absence of online vision at frequencies between 4 and $10 \mathrm{~Hz}$ (e.g., de Grosbois \&

114 Tremblay, 2016; de Grosbois \& Tremblay, 2017; de Grosbois \& Tremblay, 2018). Additionally, a

115 second frequency peak that differentiated performance across the same vision conditions has also

116 been observed between approximately 17 and 20 Hz (e.g., de Grosbois \& Tremblay, 2017; de

117 Grosbois \& Tremblay, 2018). This second peak was proposed to represent a non-visual process

118 because its relative contribution to performance was found to increase in the absence, rather than

119 in the presence of online vision. Although there is ample evidence that proprioception can

120 mediate online control processes (e.g., Goodman et al., 2018; Gosselin-Kessiby, Messier, \&

121 Kalaska, 2008), de Grosbois and Tremblay (2018) proposed that this second peak may reflect a

122 strategic change in the manner in which the reaching movements were planned and controlled.

123 Indeed, strategic changes in movement planning have been shown to alter the contributions of

124 online control processes (e.g., Roberts, Burkitt, Elliott, \& Lyons, 2016). Such a multifaceted

125 organization of online reaching performance is consistent with contemporary models of online

126 control (e.g., Elliott et al., 2010; Elliott et al., 2017). However, a direct association between the

acceleration profile of a discrete aiming movement. 
127 higher, secondary peak and non-visual online control processes has only been implied.

128 Additionally, the association of the lower frequency peak and visuomotor online control

129 processes have been based solely on manipulations of the availability of vision. One possible

130 avenue to address both of these potential issues is the combining of vision availability with

131 accuracy-based instruction sets.

132 Because reaching performance can be significantly influenced by instruction sets (e.g.,

133 Adam, 1992; Elliott et al., 1991; Zhai, Kong, \& Ren, 2004), the influence of strategic instruction

134 sets could be used to further evaluate the nature of the frequency peaks observed in de Grosbois

135 and Tremblay (2017). Accordingly, the primary purpose of the current study was to further

136 investigate the nature of the visual and non-visual control mechanisms attributed to the lower and

137 higher frequency peaks reported in de Grosbois and Tremblay (2017; see also de Grosbois \&

138 Tremblay, 2018). To this end, two experiments were completed wherein manipulations of the

139 availability of online vision (i.e., full-vison; FV and no-vision; NV) were paired with two

140 different instruction sets (i.e., low and high accuracy instructions). Further, the scheduling of the

141 availability of vision was presented in either a blocked (i.e., Experiment 1) or randomized

142 fashion (i.e., Experiment 2). Participants were instructed to either focus on being as accurate as

143 possible (i.e., high-accuracy instruction) or to simply land in the general vicinity of the target

144 (i.e., low-accuracy instruction). Although blocked and randomized trial scheduling likely

145 influence both the planning and the online control of reaches (e.g., Khan, Chua, Elliott, Coull, \&

146 Lyons, 2002), it was presumed that under a randomized trial scheduling that differences between 
147 vision conditions could be more directly attributable to the contributions of online control (i.e.,

148 plan consistently for the worst-case scenario; e.g., Elliott, Hansen, Mendoza, \& Tremblay, 2004).

149 The primary analysis was completed using the aforementioned pPower frequency-domain

150 analyses. However, to validate both the primary manipulations and the pPower measure,

151 additional performance variables were also assessed. These additional measures included average

152 movement endpoint, variable error, time after peak limb velocity, and $\mathrm{Z}^{2}$ correlations. Notably,

153 the latter three have been directly associated with online control. Overall, it was first

154 hypothesized that endpoint accuracy (i.e., endpoint position / constant-error) would improve both

155 with vision available and with accuracy-focused instruction sets. Likewise, it was hypothesized

156 that all the dependent measures previously associated with online control would indicate a

157 greater contribution of online control when online vision was available, and with instructions to

158 be accurate. That is, under both full-vision conditions and high accuracy instruction sets,

159 endpoint variability and $\mathrm{Z}^{2}$ correlations were hypothesized to be smaller, whereas, the time spent

160 after peak-limb velocity was expected to increase (e.g., Elliott et al., 1991). Lastly, and most

161 relevant to the primary purpose of the current study, it was hypothesized that if the relative

162 magnitudes of the lower and higher frequency peaks in the pPower spectra represent the relative

163 contribution of visual and non-visual control processes to reaching performance, then the visual

164 process was expected to be facilitated in the full-vision condition, and the non-visual process was

165 expected to be facilitated in the no-vision condition. Notably, instructions to produce accurate

166 movements were expected to enhance these effects. 


\section{Methods}

168

169

170

171

172

173

174

175

176

177

178 179 both experiments.

180

181

182

183

184

185

186

\section{Power Analysis}

\section{Participants}

An a-priori power analysis was conducted to determine the expected minimum required sample size for the current study. The analysis was undertaken using the G*power software (see: Faul, Erdfelder, Lang, \& Buchner, 2007; version 3.1.9.2) and was based on the results reported by de Grosbois and Tremblay (2017). Partial eta squared effect sizes for the main effect of vision condition at the lower and higher frequency peaks were computed using the reported $F$ statistics (e.g., Bakeman, 2005). Alpha (i.e., $\alpha$ ) was set to .05 and power (i.e., $\beta$ ) was set to .95 . The analysis indicated that the minimum required participants was 7 for the analysis of the lower frequency peak and 5 for the analysis of the higher frequency peak. Given that this analysis was computed based on the results of a single published study, it was anticipated that the effect sizes reported could have been overestimates, and as such, additional participants were collected in

Twelve participants were recruited for Experiment 1 ( 5 males; 7 females; age range 18 to 31), and 12 new participants were recruited for Experiment 2 (5 males; 7 females; age range 18 to 36). All were right-handed as determined by a modified version of a handedness questionnaire (Oldfield, 1971). Informed written consent was obtained prior to the beginning of the experimental trials. Monetary compensation was provided in the amount of \$5 CAD upon completion the protocol, which lasted approximately 30 minutes. All procedures were approved 
187 by the local research ethics board.

\section{Materials and apparatus}

189 The experimental procedures were completed in a dimly lit room wherein participants sat 190 at a desk in front of a custom aiming console (i.e., console dimensions: length $=51 \mathrm{~cm}$; width =

$19128 \mathrm{~cm}$; height $=9 \mathrm{~cm})$. The console was oriented such that its long axis extended in the

192 participant's medial-lateral plane (see Figure 1). Participants also positioned their head in a chin-

193 rest, extending approximately $29 \mathrm{~cm}$ above the surface of the aiming console. The shorter edge

194 of the aiming console was aligned with the centre of the chin-rest. A 1 by $1 \mathrm{~cm}$ of Velcro ${ }^{\mathrm{TM}}$ patch

195 served as the home position and was positioned approximately $40 \mathrm{~cm}$ to the right of the chin rest.

196 A small (i.e., approximately 0.5 by $0.5 \mathrm{~cm}$ ) green light emitting diode (LED) served as the target,

197 and was located $30 \mathrm{~cm}$ to the left of the home position and below the surface of the aiming

198 console. Notably, the LED became visible to participants only when illuminated. Also, a piezo-

199 electric buzzer (Mallory Sonalert Products, Inc., Indianapolis, IN, USA) was utilized to provide

200 an auditory go-signal during the experiment.

201 The availability of visual information of the environment was manipulated via liquid-

202 crystal goggles (i.e., PLATO, Translucent Technologies Inc., Toronto, ON, CA: Milgram, 1987).

203 The goggles could take two states: 1) transparent / open whereby they permitted vision of the

204 environment; or 2) translucent / closed whereby they withheld vision of the environment.

205 Both position and acceleration data were collected during movements at a concurrent 206 sampling rate of $250 \mathrm{~Hz}$. The position data were acquired using an optoelectric motion tracking 
207 system (i.e., Optotrak Certus, Northern Digital Inc., Waterloo, ON, Canada), which tracked the 208 position of the participant's right index finger via an infrared light emitting diode (IRED). The

209 acceleration data were acquired via a triple-axis accelerometer (i.e., MMA7361L; NXP

210 Semiconductors, Eindhoven, Netherlands) embedded in an orthotic wrist-brace worn by the

211 participant on their right hand (i.e., model 225ZZ; Life Brand, Toronto, ON, Canada). One of the

212 three axes of the accelerometer was oriented with the primary direction of movement (i.e., the

213 medial-lateral axis). Data from the accelerometer was sampled with a multi-function data

214 acquisition card (i.e., model PCI-6042E, National Instruments Inc., Austin, TX, USA). Custom

215 MATLAB scripts (The Mathworks Inc., Natick, MA, USA) controlled the experimental

216 procedures and devices.

\section{Design and procedures}

218 Each trial commenced with the participant resting their right-index finger at the home

219 position. The target LED was illuminated and the goggles were open (i.e., transparent) for a

220 variable foreperiod of 1 to $1.5 \mathrm{~s}$, after which an auditory go-signal was sounded (i.e., $50 \mathrm{ms,}$

$2212900 \mathrm{~Hz}$ ). Movement start was defined as the first occurrence of limb velocity greater than 30

$222 \mathrm{~mm} / \mathrm{s}$ that was maintained for at least $12 \mathrm{~ms}$ following the go-signal. In the full-vision condition,

223 the goggles remained open until movement end. Movement end was calculated as the first

224 occurrence of a limb velocity less than $30 \mathrm{~mm} / \mathrm{s}$ that lasted for at least $20 \mathrm{~ms}$ (i.e., five samples)

225 following movement start. The no-vision condition progressed in a similar manner as the full-

226 vision condition up to the moment of movement start, at which the goggles closed and remained 
227 closed for the remaining duration of the trial. The goggles remained in the closed state until the 228 start of the next trial (i.e., the participant returned to the home position without vision and 229 received no explicit visual terminal feedback). In addition to the manipulation of the availability 230 of vision, two instruction sets were employed.

In the high-accuracy instruction set, participants were told to try to be as accurate as 232 possible, within a 400 to $500 \mathrm{~ms}$ movement time bandwidth. Note that the $500 \mathrm{~ms}$ duration was 233 critical for the frequency analyses (see below) and that reaches taking more than 512 ms (or less 234 than $400 \mathrm{~ms}$ ) were re-run. In the low-accuracy instruction set, participants were told to land in 235 the general vicinity of the target, while maintaining the same movement time band width (i.e., 236400 to $500 \mathrm{~ms}$ ). This latter condition was conceptually comparable to the "automatic" condition 237 employed by Woodworth (1899) in that online vision was available, but participants were 238 instructed not to focus on completing accurate movements. In Experiment 1, the two vision 239 conditions and the two instruction sets were arranged in four blocks of 30 trials, and scheduled in 240 a blocked organization. Four block orders were utilized and counter-balanced across participants.

241 Each participant completed either two blocks of full-vision followed by two blocks of no-vision, 242 or the reverse. Within the two blocks of each vision condition, the instruction sets were also 243 counter-balanced. In Experiment 2, the vision conditions were presented in a randomized trial 244 schedule, while the instruction sets remained in separate blocks of trials. Thus, two blocks of 60 245 trials were completed, which were counterbalanced across participants. To prevent carry-over 246 effects across trials (e.g., Cheng, Luis, \& Tremblay, 2008), the vision condition scheduling was 
247 pseudo-randomized in that the same vision condition could not be repeated on more than two

248 consecutive trials. In both experiments, participants completed a minimum of 10 familiarization

249 trials in the condition associated with the first block to get comfortable with the required

250 movement time bandwidth. Both experiments included a total of 120 experimental trials, and

251 lasted approximately half an hour.

\section{Data processing and analysis}

Based on previous work (i.e., de Grosbois \& Tremblay, 2017; de Grosbois \& Tremblay

254 2018) four dependent measures of online control were chosen and calculated to evaluate

255 performance. Variable error (i.e., VE) was computed as the within-condition standard deviation

256 of the movement endpoints in the primary movement axis. Smaller VE values have been

257 associated with an increased contribution of online control processes (e.g., Tremblay, et al., 258 2013).

Time after peak velocity (i.e., TAPV) was computed as the number of milliseconds

260 elapsed between the sample at which peak limb velocity was reached and the sample at

261 movement end. Longer TAPV values have been associated with a greater contribution of online

262 control processes (e.g., Binsted, Brownell, Vorontsova, Heath, \& Saucier, 2007; Elliott et al.,

263 1991; Hansen, Glazebrook, Anson, Weeks, \& Elliott, 2006; Soechting, 1984).

Third, a correlational measure of online control was computed as within-condition correlations across trials between the position attained at $75 \%$ of movement time, and the 
267 fisher-transform and squared (i.e., Z2: e.g., Bernier et al., 2006; de Grosbois \& Tremblay, 2016; 268 de Grosbois \& Tremblay, 2017; de Grosbois \& Tremblay, 2018). Smaller correlational values

269 have been interpreted as evidence of a greater contribution of online control (e.g., de Grosbois \& 270 Tremblay, 2016; Heath, 2005; Heath, Westwood, Binsted, 2004).

Lastly, proportional power spectra were computed from the acceleration profiles of each

272 trial (i.e., pPower; see de Grosbois \& Tremblay, 2016; de Grosbois \& Tremblay, 2017; de

273 Grosbois \& Tremblay, 2018). These spectra were attained via a multi-step process. First, using

274 the MATLAB polyfit() and polyval() functions, the best fitting $5^{\text {th }}$ order polynomial was

275 determined and computed for each acceleration trace. This best fitting polynomial was then

276 subtracted from the acceleration trace yielding residuals. Second, a Hanning truncation window

277 of the same duration as the movement was generated via the MATLAB hanning() function, and

278 was multiplied by the residuals to reduce edge effects and spectral leakage (e.g., Randall, 2008;

279 Warner, 1998). Third, the data were converted into a frequency domain representation via a fast-

280 fourier-transform (i.e., FFT; MATLAB fft() function) with a transform length of 128 samples

281 (i.e., movement times up to $512 \mathrm{~ms}$ ). The output of the FFT was converted into a power spectrum

282 by multiplying the Fourier coefficients by their complex conjugate (i.e., via the MATLAB conj()

283 function) and dividing by the transform length. These spectra were then normalized by the total

284 power up to the Nyquist frequency (i.e., $125 \mathrm{~Hz}$ ), and expressed as a relative percent contribution

285 of resolvable frequencies to the residual variance (i.e., the pPower spectrum)2. The pPower

2 See the appendix of de Grosbois (2017) for a MATLAB script outlining the main analysis. 
Accuracy instructions and online control

286 spectra were subsequently evaluated qualitatively for apparent peaks on a trial-by-trial basis.

287 Both the frequency and the relative magnitude of such peaks were separately subjected to further 288 analyses. Greater relative magnitudes of observed peaks in pPower spectra at $10 \mathrm{~Hz}$ and below 289 have been associated with a greater relative contribution online visuomotor control (e.g., the $\alpha$ 290 peak; see de Grosbois \& Tremblay, 2017; de Grosbois \& Tremblay, 2018), and greater relative 291 magnitudes of observed peaks in pPower spectra between approximately 17 and $20 \mathrm{~Hz}$ have been 292 associated with the contribution of a non-visual process (e.g., the $\beta$ peak; see de Grosbois \& 293 Tremblay, 2017; de Grosbois \& Tremblay, 2018). Thus, to ensure the capture of both peaks, 294 frequency spectra were evaluated up to $30 \mathrm{~Hz}$.

295 The main analyses were computed separately for each experiment for all dependent 296 variables as a 2 Vision Condition (full-vision, no-vision) x 2 Instruction Set (high-accuracy, low297 accuracy) repeated-measures ANOVA. In the event of a significant interaction between Vision 298 Condition and Instruction Set, pairwise comparisons were completed across the two levels of 299 each factor. In this case, a Bonferroni correction was applied to $p$-values based on the number of $300 t$-tests completed (i.e., 4). The corrected $p$-values have been reported in the results section as $p_{\mathrm{b} 4}$ 301 where the ' $\mathrm{b}$ ' indicated that a Bonferroni correction has been applied, and the '4' indicated the 302 number of comparisons corrected for. Statistical significance was determined at $p<.05$ for all 303 analyses. The effect size reported for each ANOVA was generalized eta squared $\left(\eta_{\mathrm{G}}{ }^{2}\right.$; see 304 Bakeman, 2005; Olejnik \& Algina, 2003). The ANOVAs were computed using the EZ package 305 (Lawrence, 2013) in the R statistics program (version 3.1.2; R-core Team, 2014). All error bars 
306 depicted in figures represent within-subject $95 \%$ confidence intervals (see Loftus \& Masson, 307 1994).

\section{Results}

A summary of all condition's means and standard deviations for all dependent variables

310 can be found in Table 1.

\section{Experiment 1: Blocked vision conditions}

The analysis of average movement endpoint in the primary movement axis yielded no

313 significant effects or interactions, $F \mathrm{~s}(1,11)<2.16, p \mathrm{~s}>.160, \eta_{\mathrm{G}}{ }^{2} \mathrm{~s}<.060$. The grand mean

314 endpoint position was $307.8 \mathrm{~mm}(S D=5.8)$.

316 significant main effect of Vision Condition, $F(1,11)=97.93, p<.001, \eta_{\mathrm{G}}{ }^{2}=.529$. Performance

317 in the full-vision conditions yielded significantly smaller VE values (i.e., $M=4.68 \mathrm{~mm}, S D=$

3180.92 ) relative to the no-vision conditions (i.e., $M=8.59 \mathrm{~mm}, S D=1.66$ ). No significant main

319 effect or interaction involving Instruction Set was observed, $F \mathrm{~s}(1,11)<3.13, p \mathrm{~s}>.104, \eta_{\mathrm{G}}{ }^{2} \mathrm{~s}<$ 320.085.

322 significant effects or interactions, $F \mathrm{~s}(1,11)<1.78, p \mathrm{~s}>.110, \eta_{\mathrm{G}}{ }^{2} \mathrm{~s}<.013$. The grand mean TAPV 323 was $288 \mathrm{~ms}(S D=20)$.

324 The analysis of the $\mathrm{Z}^{2}$ correlations yielded a significant main effect of Vision Condition, 
$325 F(1,11)=34.12, p<.001, \eta_{\mathrm{G}}^{2}=.454$. Performance in the full-vision conditions yielded 326 significantly smaller $\mathrm{Z}^{2}$ values (i.e., $M=0.29, S D=0.15$ ) relative to the no-vision conditions 327 (i.e., $M=1.15, S D=0.48$ ). No significant main effect or interaction involving Instruction Set was observed, $F \mathrm{~s}(1,11)<0.34, p \mathrm{~s}>.570, \eta_{\mathrm{G}}{ }^{2} \mathrm{~s}<.007$

Prior to the analysis of the pPower data, the spectra were qualitatively examined for 330 observable peaks (see Figure 2, panel a). As in de Grosbois and Tremblay (2017; see also de

331 Grosbois \& Tremblay, 2018), two peaks were evident: 1) one in the relatively lower frequencies, 332 denoted as the alpha peak ( $\left.\alpha_{\text {Peak }}\right)$; and 2$)$ one in the relatively higher frequencies, denoted as the 333 beta peak $\left(\beta_{\text {Peak }}\right)$. Analysis of the frequency of the $\alpha_{\text {Peak }}$ resulted in no significant effects or 334 interactions, $F_{\mathrm{S}}(1,11)<4.32, p \mathrm{~s}>.062, \eta_{\mathrm{G}}^{2} \mathrm{~s}<.035$. The grand mean frequency of the $\alpha_{\text {Peak }}$ was 335 $7.17 \mathrm{~Hz}(S D=0.62)$. Analysis of the relative magnitude of the $\alpha_{\text {Peak }}$ resulted in main effects of Vision Condition, $F(1,11)=13.18, p=.004, \eta_{\mathrm{G}}{ }^{2}=.235$, and Instruction Set, $F(1,11)=11.90, p=$ $337.005, \eta_{\mathrm{G}}{ }^{2}=.022$ (see Figure 2, panel b). In the full-vision conditions, the relative magnitude of 338 the $\alpha_{\text {Peak }}$ was significantly larger (i.e., $M=25.37 \%, S D=3.81$ ) compared to the no-vision 339 conditions (i.e., $M=20.68 \%, S D=4.43$ ). Additionally, the relative magnitude of the $\alpha$ Peak was 340 also significantly larger with the high-accuracy instruction set (i.e., $M=23.66 \%, S D=3.70$ )

341 relative to the low-accuracy instruction set (i.e., $M=22.39 \%, S D=3.36$ ). No significant 342 interaction was observed between Vision Condition and Instruction Set, $F(1,11)=0.42, p=.531$, $343 \eta_{\mathrm{G}}^{2} \mathrm{~s}=.004$ 
345 this peak was estimated based on the associated frequency observed in the no-vision conditions.

346 The resulting preliminary analysis of the frequency of the $\beta_{\text {Peak }}$ across the two no-vision

347 conditions revealed no significant effect of Instruction Set, $F(1,11)=1.73, p=.215, \eta_{\mathrm{G}}{ }^{2}=.020$.

348 The grand mean frequency for the $\beta_{\text {Peak }}$ in the no-vision conditions was $18.27 \mathrm{~Hz}(S D=0.80)$.

349 The nearest resolvable frequency (i.e., $17.58 \mathrm{~Hz}$ ) was chosen to represent the relative magnitude

350 of the $\beta_{\text {Peak }}$ in the forthcoming relative magnitude analysis for the two full-vision conditions. The

351 analysis of the relative magnitude of the $\beta_{\text {Peak }}$ resulted in a main effect of Vision Condition,

$352 F(1,11)=45.10, p<.001, \eta_{\mathrm{G}}^{2}=.562$ (see Figure 2, panel c). Reaches completed in the full-

353 vision conditions yielded a significantly smaller pPower magnitude at the $\beta_{\text {Peak }}$ frequency peak

354 (i.e., $M=2.20 \%, S D=1.02$ ) relative to those completed in the no-vision conditions (i.e., $M=$

$3554.81 \%, S D=1.21)$. No significant main effect or interaction involving Instruction set was

356 observed, $F \mathrm{~s}(1,11)<0.93, p \mathrm{~s}>.817, \eta_{\mathrm{G}}{ }^{2} \mathrm{~s}<.005$.

In summary, when the vision conditions were employed in separate blocks of trials, the availability of online vision (i.e., vision during the movement) led to smaller endpoint variability,

359 lower $\mathrm{Z}^{2}$ correlation values, larger $\alpha_{\text {Peak }}$ magnitudes, and smaller $\beta_{\text {Peak }}$ magnitudes. In contrast, 360 neither endpoint position in the primary movement axis, nor time spent following peak limb

361 velocity were significantly influenced by the vision manipulation. The inclusion of the high-

362 accuracy instruction set significantly increased the $\alpha_{\text {Peak }}$ magnitude only. That is, no other

363 dependent measure was significantly modulated by the Instruction Set manipulation. Further, 364 none of the dependent measures exhibited an interaction between the two manipulations of 
Accuracy instructions and online control

365 Vision Condition and Instruction Set.

\section{Experiment 2: Randomized vision conditions}

367 The analysis of the average movement endpoint in the primary movement axis yielded a 368 significant main effect of Vision Condition, $F(1,11)=13.10, p=.004, \eta_{\mathrm{G}}{ }^{2} \mathrm{~s}=.247$. Performance

369 in the full-vision conditions exhibited a significantly farther mean endpoint position (i.e., $M=$

$370309.9 \mathrm{~mm}, S D=2.8$ ) relative to the no-vision conditions (i.e., $M=303.3 \mathrm{~mm}, S D=7.6$ ). No

371 significant main effect or interaction involving Instruction Set was observed, $F_{\mathrm{s}}(1,11)<3.50, p \mathrm{~s}$

$372>.090, \eta_{\mathrm{G}}^{2} \mathrm{~s}<.021$.

373 The analysis of variable error in the primary movement axis (i.e., VE) yielded a

374 significant main effect of Vision Condition, $F(1,11)=43.72, p<.001, \eta_{\mathrm{G}}{ }^{2}=.273$. Performance

375 in the full-vision conditions yielded significantly smaller VE values (i.e., $M=4.63 \mathrm{~mm}, S D=$

376 1.64) relative to the no-vision conditions (i.e., $M=6.85 \mathrm{~mm}, S D=1.15$ ). No significant main

377 effect or interaction involving Instruction Set was observed, $F \mathrm{~s}(1,11)<3.03, p \mathrm{~s}>.101, \eta_{\mathrm{G}}^{2} \mathrm{~s}<$ $378 \quad .080$

379

The analysis of the time spent following peak limb velocity (i.e., TAPV) resulted in a

380 significant effect of Vision Condition, $F(1,11)=7.33, p=.020, \eta_{\mathrm{G}}{ }^{2} \mathrm{~s}<.068$. Performance in the

381 full-vision conditions yielded significantly longer TAPV values (i.e., $M=294 \mathrm{~ms}, S D=15$ )

382 relative to the no-vision conditions (i.e., $M=286 \mathrm{~ms}, S D=14$ ). No significant main effect of

383 Instruction Set was observed, $F(1,11)=1.90, p=.195, \eta_{\mathrm{G}}{ }^{2}=.024$. Additionally, because the

384 interaction between Vision Condition and Instruction Set neared conventional levels of statistical 
385 significance, $F(1,11)=4.74, p=.052, \eta_{\mathrm{G}}^{2}=.009$, post-hoc pairwise comparisons were 386 completed. This subsequent analysis revealed that a sole significant difference was observed in 387 the high-accuracy Instruction Set, indicating significantly longer TAPV values in the full-vision 388 relative to the no-vision condition (i.e., full-vision: $M=298 \mathrm{~ms}, S D=15$; no-vision: $M=287$ $\left.389 \mathrm{~ms}, S D=14 ; p_{\mathrm{b} 4}=.025\right)$. Conversely, the contrast between vision conditions did not reach 390 significance in the low-accuracy Instruction Set (full-vision: $M=290 \mathrm{~ms}, S D=18$; no-vision: $M$ $\left.391=285 \mathrm{~ms}, S D=16 ; p_{\mathrm{b} 4}=.565\right)$.

The analysis of the $\mathrm{Z}^{2}$ correlations yielded a significant main effect of Vision Condition,

$393 F(1,11)=23.10, p<.001, \eta_{\mathrm{G}}{ }^{2}=.220$. Performance in the full-vision conditions yielded 394 significantly smaller $\mathrm{Z}^{2}$ values (i.e., $M=0.39, S D=0.34$ ) relative to the no-vision conditions 395 (i.e., $M=0.88, S D=0.36$ ). No significant main effect or interaction involving Instruction Set 396 was observed, $F \mathrm{~s}(1,11)<1.85, p \mathrm{~s}>.602, \eta_{\mathrm{G}}^{2} \mathrm{~s}<.050$.

397 As was the case in Experiment 1, alpha $\left(\alpha_{\text {Peak }}\right)$ and beta peaks $\left(\beta_{\text {Peak }}\right)$ were observable in 398 the spectra (see Figure 3, panel a). Analysis of the frequency of the $\alpha_{\text {Peak }}$ resulted in no 399 significant effects or interactions, $F \mathrm{~s}(1,11)<1.61, p \mathrm{~s}>.231, \eta_{\mathrm{G}}{ }^{2} \mathrm{~s}<.027$. The grand mean 400 frequency of the $\alpha$ Peak was $6.92 \mathrm{~Hz}(S D=0.49)$.

$401 \quad$ Analysis of the relative magnitude of the $\alpha_{\text {Peak }}$ resulted in a main effect of Vision 402 Condition, $F(1,11)=26.98, p<.001, \eta_{\mathrm{G}}{ }^{2}=.223$. In the full-vision conditions, the relative 403 magnitude of the $\alpha_{\text {Peak }}$ was significantly larger (i.e., $M=31.82 \%, S D=3.10$ ) relative to the no404 vision conditions (i.e., $M=28.39 \%, S D=2.70$ ). Also, the main effect of Instruction Set did not 
405 reach conventional levels of statistical significance, $F(1,11)=3.59, p=.085, \eta_{\mathrm{G}}{ }^{2}=.059$ (see 406 Figure 3, panel b). However, the pattern of means was consistent with the Experiment 1 findings 407 (i.e., high-accuracy instruction set: $M=30.91 \%, S D=3.11$; low-accuracy instruction set: $M=$ 408 $29.30 \%, S D=2.98)$. Additionally, no significant interaction between Vision Condition and Instruction Set was observed, $F(1,11)<0.01, p=.989, \eta_{\mathrm{G}}{ }^{2}<.001$. Because no observable $\beta_{\text {Peak }}$ was present for the full-vision conditions, the frequency of

411 this peak was again estimated based on the two no-vision conditions. The analysis of the two no412 vision conditions revealed no significant effect of Instruction Set, $F(1,11)=0.16, p=.694, \eta_{\mathrm{G}}{ }^{2}=$ 413.003 . The grand mean frequency for the $\beta_{\text {Peak }}$ in the no-vision conditions was $17.75 \mathrm{~Hz}(S D=$ 414 0.95). The nearest resolvable frequency (i.e., $17.58 \mathrm{~Hz}$ ) was chosen to represent the relative 415 magnitude of the $\beta_{\text {Peak }}$ in the forthcoming analysis for the two full-vision conditions.

416 The analysis of the relative magnitude of the $\beta$ Peak resulted in main effects of both Vision 417 Condition, $F(1,11)=108.45, p<.001, \eta_{\mathrm{G}}^{2}=.647$, and Instruction Set, $F(1,11)=8.51, p=.014$, $418 \eta_{\mathrm{G}}{ }^{2}=.152$ (see Figure 3, panel c). Reaches completed in the full-vision conditions yielded a 419 significantly smaller $\beta_{\text {Peak }}$ (i.e., $M=1.47 \%, S D=0.42$ ) relative to the no-vision conditions (i.e., $420 M=3.60 \%, S D=0.84)$. Additionally, reaches completed under the high accuracy instruction set 421 yielded a significantly smaller $\beta_{\text {Peak }}$ (i.e., $M=2.20 \%, S D=0.51$ ) relative to the low accuracy 422 instruction set (i.e., $M=2.86 \%, S D=0.83$ ). Additionally, no significant interaction between 423 Vision Condition and Instruction Set was observed, $F(1,11)<0.01, p=.988, \eta_{\mathrm{G}}^{2}<.001$. 
425 trials, the availability of online vision (i.e., vision during the movement) led to farther endpoint 426 positions, smaller endpoint variability, longer times spent after peak limb velocity, lower $\mathrm{Z}^{2}$

427 correlation values, larger $\alpha_{\text {Peak }}$ magnitudes, and smaller $\beta_{\text {Peak }}$ magnitudes. In contrast to

428 Experiment 1 (i.e., blocked trial schedule), the inclusion of the high-accuracy instruction set

429 significantly decreased the $\beta_{\text {Peak }}$ magnitude. No other dependent measure was significantly

430 modulated by the Instruction Set manipulation. Further, the main effect of Vision Condition

431 observed for time spent after peak limb velocity was likely mediated by the near-significant

432 interaction between the Vision Condition and Instruction Set (i.e., $p=.052$ ). That is, only when

433 online vision was available with a high accuracy instruction set were longer times after peak

434 limb velocity observed.

\section{Discussion}

The current study sought to gain further insight into the nature of the processes contributing to the lower and higher frequency peaks previously observed in pPower spectra during full-vision and no-vision conditions respectively. This aim was accomplished via three main experimental manipulations: 1) the availability of online vision during reaching (i.e., fullvision and no-vision conditions); 2) the application of two instructions sets (i.e., high-accuracy

441 and low-accuracy instructions); and 3) the predictability of online vision through blocked and 442 randomized trial scheduling across experiments. It was hypothesized that if the processes

443 associated with the two frequency peaks represented error-reducing online control mechanisms, 444 then their contributions to reaching performance would be enhanced in full-vision (i.e., the lower 
445 frequency peak) and no-vision (i.e., the lower frequency peak) conditions. Further, the addition 446 of accuracy-focused instruction sets was anticipated to enhance these contributions. Lastly, the

447 inclusion of a randomized trial scheduling with respect to vision conditions was expected to 448 better isolate the contributions of control mechanisms by encouraging comparable planning 449 across conditions. In most cases, these manipulations worked as expected, with the exception of 450 the influence of accuracy-based instructions on the contributions of the non-visual frequency 451 peak (i.e., the $\beta_{\text {Peak }}$ ). That is, the instructions to produce accurate movements suppressed the 452 contributions of this higher frequency process, rather than enhance it. Thus, it appears that the 453 visual and non-visual processes associated with the lower and higher frequency peaks in the 454 pPower spectra represent processes that differ not only in their target modality, but also the 455 nature of their normal contribution to online reaching performance.

To better associate the frequency peaks with corrective, online control processes, 457 reaching performance was first evaluated using more traditional measures of performance. 458 Considering average endpoint position, no significant differences were observed when the trial 459 scheduling was blocked. However, when randomized trial scheduling was utilized, significantly 460 shorter amplitude movements were observed in the no-vision vs. the full-vision conditions. Thus, 461 in a situation of relative uncertainty regarding the possibility of visual feedback, participants 462 completed their movements in a manner consistent with a conservative strategy associated with 463 planning for the worst-case scenario (e.g., Elliott, et al., 2004; Hansen et al., 2006). That is, given 464 the time constraints, target overshoots may be particularly costly, especially if visual feedback 
465 were not to be available (e.g., Elliott et al., 2010, 2017). These results can be contrasted with 466 those of Elliott et al. (2014), who recently reported that such undershooting could be maximized

467 by using blocked trial scheduling with situations wherein overshoots would be more costly (i.e., 468 a downward movement) without the provision of terminal feedback. The failure to replicate 469 those findings in the current study likely stems from a combination of factors including the 470 temporal constraints, and the use of only one potential target. That latter of which likely led to 471 enhanced performance on a trial-to-trial basis. Nevertheless, performance differences observed in 472 Experiment 2 likely better reflected differences in the utilization of online control across vision 473 conditions. Subsequent analyses specifically addressed this possibility.

First, endpoint variability was significantly smaller in the presence of online visual 475 information, which was expected (e.g., Elliott et al., 1991; Heath, 2005; de Grosbois \& 476 Tremblay, 2016; Zelaznik et al., 1983). Unexpectedly, the instructions to be accurate did not 477 result in significant decreases in endpoint variability (cf., Adam, 1992; Elliott et al., 1991; Zhai et 478 al., 2004). Yet, the pattern of results was in the expected direction for both experiments. High 479 accuracy instructions tended toward smaller endpoint variability values. Notably, however, the 480 magnitude of the variable error in the absence of online vision was apparently smaller when the 481 trial scheduling was randomized (i.e., $6.8 \mathrm{vs} 8.6 \mathrm{~mm}$ ). Such reductions in variable error could 482 result from a carry-over effect of performance on full-vision trials into performance on the 483 subsequent no-vision trials when using a randomized schedule (e.g., Cheng et al., 2008). This 484 benefit may have accrued in part, from partial terminal feedback available due to the closing of 
485 the goggles at movement end (cf. earlier). This would allow for even greater similarity in the 486 planning mechanisms across vision conditions in Experiment 2.

487 Second, the analysis of the time spent following peak limb velocity did not exhibit any 488 significant effects or interactions when vision conditions were blocked. Although increased times 489 spent following peak limb velocity (TAPV) has been associated with visual feedback utilization 490 (e.g., Elliott et al., 1991), this finding has not been consistently replicated (e.g., de Grosbois \& 491 Tremblay, 2016; de Grosbois \& Tremblay, 2017; de Grosbois \& Tremblay, 2018; Heath, et al., 492 2004). In contrast, when vision conditions were randomized, a main effect of vision condition 493 was observed. That is, longer TAPV values were observed in the presence relative to the absence 494 of online vision. That is, participants likely incurred a cost associated with using online visual 495 feedback when they had not planned to (see Kennedy, Bhattacharjee, Hansen, Reid, and 496 Tremblay, 2015; see also Tremblay et al., 2013; cf., Hansen et al., 2006). Notably, the absence of 497 this effect for the blocked vision conditions in Experiment 1 strengthens the notion that TAPV is 498 influenced both by changes in planning and online control (see also de Grosbois \& Tremblay, 499 2018; Plamondon \& Alimi, 1992). Furthermore, it also strengthens the notion that changes motor 500 planning mechanisms may influence online control processes (e.g., Khan et al., 1998; Khan et 501 al., 2002; Roberts et al., 2016). It was also hypothesized that TAPV would increase with instructions to be accurate (e.g., 503 Adam, 1992; Elliott et al., 1991). Nevertheless, no significant differences were observed between 504 instruction set conditions for either the blocked or the randomized vision condition experiments. 
505 Yet, the pattern of means was in the expected direction for both experiments.

506

507

508

509

510

511

512

513

514

515

516

517
Third, the $\mathrm{Z}^{2}$ analysis yielded only a significant effect only of Vision Condition in both experiments. That is, the presence of online visual information during movement yielded greater estimates of online control. Such an influence of online vision on this correlational measure was expected and has been replicated many times (e.g., de Grosbois \& Tremblay, 2016; de Grosbois \& Tremblay, 2017; de Grosbois \& Tremblay, 2018; Heath, 2005; Heath et al., 2004; Khan, Lawrence, Franks, \& Buckolz, 2004; Tremblay, et al., 2013; cf., Bernier et al., 2006). In contrast, the effect of Instruction Set was not found to be statistically significant, although the observed pattern of means was in the expected direction for both experiments.

The overall meagre influence of instructions on these dependent measures, relative to previous studies (e.g., Adam, 1992; Elliott et al., 1991), may have stemmed from the added temporal accuracy demand in the current study. That is, participants were instructed to move with a movement time bandwidth between 400 and 500 ms. Thus, participants may have inadvertently placed a stronger emphasis on the temporal aspect of the task rather than the spatial aspect. Additionally, differences in how the participants interpreted the instruction sets may have added to the observed variability in performance. However, despite the lack of significant differences for most of the dependent variables, the patterns of the means in all cases were consistent with an increased emphasis on movement accuracy. Nevertheless, such an influence of the temporal demands did not interfere with the pPower analyses, thereby providing greater validity to the instruction set manipulation overall. 
Fourth and last, the analysis of the relative magnitude of the $\alpha_{\text {Peak }}$ when vision conditions were blocked indicated a significant increase in the contribution of online control processes in

527 the presence of online vision and in the high-accuracy instructions conditions. Increased power at 528 this peak has been previously associated with a greater relative contribution of visuomotor online 529 control mechanisms (e.g., de Grosbois \& Tremblay, 2017; de Grosbois \& Tremblay, 2018).

530 Notably, the increase in the high-accuracy instructions was unique across all measures.

531 Importantly, the pPower analysis has been shown to be relatively more robust to planning-

532 induced changes on the quantification of the contribution of online control as compared to the 533 other considered measures (de Grosbois \& Tremblay, 2018). Thus, the absence of significant

534 differences between instruction set conditions in the traditional measures may stem from changes

535 in movement planning across conditions. When vision conditions were randomized in

536 Experiment 2, a comparable influence of online visual information was found. Conversely, no

537 significant effect of Instruction were observed. However, the pattern of the means, and the size of 538 the difference between the two instruction sets were consistent with the findings from 539 Experiment 1 (i.e., when vision conditions were blocked). Nevertheless, it was only the pPower 540 analysis that yielded significant differences in the expected direction in response to changes in 541 instruction sets. As such the motor planning explanation is both possible and probable.

542 Overall, because the relative magnitude of the $\alpha_{\text {Peak }}$ was modulated by instructions to be 543 accurate, the association between the magnitude of the $\alpha_{\text {Peak }}$ and the contribution of online 544 control mechanisms was strengthened. In contrast, the finding of a main effect of instruction set 
Accuracy instructions and online control

545 indicated that the $\alpha_{\text {Peak }}$ may be influenced by both visual and non-visual control processes. Such 546 an assertion is consistent with the fact that the differences observed between full-vision and no-

547 vision conditions have been in the relative magnitude, and not in the mere presence / absence of 548 the $\alpha_{\text {Peak. }}$ Potential mechanistic explanations include efferent outflow control, voluntary non-

549 visual control, and proprioceptive control (e.g., Elliott et al., 2010). However, the relative

550 contribution of these distinct processes to the relative magnitude of the $\alpha_{\text {Peak }}$ is beyond the scope

551 of the current study. Accordingly, studies manipulating proprioceptive feedback could prove 552 insightful in future investigations.

553 The analysis of the relative magnitude of the $\beta_{\text {Peak }}$ resulted in significant a main effect of

554 Vision Condition for both experiments. That is, as previously reported (e.g., de Grosbois \&

555 Tremblay, 2017; de Grosbois \& Tremblay, 2018), the relative magnitude of the $\beta_{\text {Peak }}$ was larger in

556 the absence of online visual information, as compared to when it was present. A main effect of

557 Instruction Set was also observed only when vision conditions were randomized (i.e.,

558 Experiment 2). That is, when the high-accuracy instruction set was provided, the relative

559 magnitude of the $\beta_{\text {Peak }}$ was significantly smaller relative to the low-accuracy instruction set

560 conditions. It had been hypothesized that if the $\beta_{\text {Peak }}$ represented a control mechanism modifiable

561 by changes in instructions, it would increase in both no-vision conditions and when participants

562 were instructed to be accurate. Instead, the relative magnitude of the $\beta_{\text {Peak }}$ increased with no-

563 vision conditions and decreased when accuracy was stressed in the instructions. Thus, an

564 alternative explanation is warranted. 
Instead of viewing the presence of the $\beta$ Peak as evidence for the contributions of a controlrelated process, a parsimonious alternative is that its absence reflects the contribution of an

567 inhibitory process. That is, under full-vision conditions, oscillations normally associated with

568 this secondary peak were presumably suppressed to achieve a high level of movement accuracy.

569 When online vision was not available, the decrease in contribution of visuomotor online control

570 processes lessened this suppression. Further, when visual feedback was randomized, instructions

571 to be accurate also significantly decreased the relative magnitude of the $\beta_{\text {Peak. Although it is often }}$

572 stated that, under randomized visual feedback schedules, participants plan for the worst-case

573 scenario (e.g., Elliott et al., 2004), these results indicate that it may not be so simple. Given that

574 under blocked visual feedback scheduling (i.e., Experiment 1), the $\beta_{\text {Peak }}$ was consistently larger in

575 the no-vision conditions relative to the full-vision condition, a worst-case scenario prediction for

576 Experiment 2 (i.e., randomized vision condition schedule) would be an overall $\beta_{\text {Peak }}$ magnitude

577 comparable in size to the no-vision conditions of Experiment 1. Instead, the relative magnitude

578 of the $\beta_{\text {Peak }}$ decreased in Experiment 2 relative to Experiment 13. That is, it appeared as if

579 participants were preparing for the possibility of visual feedback utilization by suppressing the

580 relative magnitude of the $\beta_{\text {Peak }}$, irrespective of the vision condition. Notably, although this

581 explanation is not entirely consistent with a plan for the worst-case scenario hypothesis, it is

582 consistent with the expectation that under randomized vision condition scheduling, participants

3 Analysis of the relative magnitude of the $\beta_{\text {Peak }}$ across experiments yielded a significant effect of Experiment, $F(1,22)=10.23, p=.004, \eta_{\mathrm{G}}{ }^{2}=.197$. That is, the relative magnitude of the $\beta$ Peak was larger in Experiment 1 (i.e., blocked scheduling; $M=3.51 \%, S D=0.90$ ) relative to Experiment 2 (i.e., randomized scheduling; $M=2.53 \%, S D=0.56$ ). 
583

584 may prepare their movements more comparably across conditions. This hypothesis of inhibition of the $\beta_{\text {Peak }}$ during movement is also consistent with existing neurophysiological data.

Fink et al. (2014) examined reaching movements in mice and reported that presynaptic inhibition of interneurons in the spinal cord were important for the maintenance of smooth reaching performance. When the specific GABA-ergic interneurons were genetically ablated, the mice exhibited forelimb oscillations in the 18 to $22 \mathrm{~Hz}$ range during movement. The authors argued that the interneurons normally reduced the gain of proprioceptive spinal feedback loops during movement. Although the current experiment examined human reaching behaviours, such an inhibitory process is consistent with the data described above. This idea of a modulation of short-latency spinal reflex pathway in a task-specific manner has previously been observed for mechanical perturbations of a reaching limb in humans (e.g., Mutha, Boulinguez, \& Sainburg, 2008). Further, such reflexes have been found to be dynamically modulated during goal-directed reaches (e.g., Liu \& Todorov, 2007). As such, it is likely that the $\beta_{\text {Peak }}$ represents the contribution of proprioceptive feedback loops, which can be suppressed in a task-relevant manner via onlinevision during reaching and / or instructions to complete accurate movements. Accordingly, future work examining the magnitude of responses to mechanical perturbations during movements paired with accuracy-based instructions could be used to directly test this hypothesis.

Overall, the influence of instruction set across the frequency peaks differed between Experiments 1 and 2. That is, when the availability of vision was provided in a blocked manner, the magnitude of the $\alpha_{\text {Peak }}$ was significantly increased with high accuracy instructions. In 
603 contrast, when the availability of vision was provided in a randomized fashion, the magnitude of

604 the $\beta_{\text {Peak }}$ was decreased with high accuracy instructions. Thus, it appears that under blocked

605 conditions, the online control process represented by the $\alpha_{\text {Peak }}$ may be up-regulated by changes in

606 movement planning. This is consistent with the idea that planning can influence the contributions

607 of online control (e.g., Khan et al., 1998; Khan, Elliott, Coull, Chua, \& Lyons, 2002; Roberts et

608 al., 2016). In contrast, under randomized conditions, it has been suggested that individuals plan

609 for the worst-case scenario (e.g., Elliott, Hansen, Mendoza, \& Tremblay, 2004; Hansen et al.,

610 2006). Indeed, the TAPV findings in Experiment 2 were consistent with this hypothesis.

611 However, the $\beta_{\text {Peak }}$ findings from Experiment 2 are not entirely consistent with this suggestion.

612 When provided with high-accuracy instructions, the magnitude of the $\beta_{\text {Peak }}$ in the no-vision

613 condition shifted closer to what one might expect from a full-vision condition. Thus, although

614 the participants may have prepared some aspects of the forthcoming movements for the worst-

615 case scenario, they also planned for the possibility of using visual feedback. Ultimately, these

616 findings suggest that the interdependency of the planning and control of reaching movements

617 more complex than previously thought.

618

619

620

62

622

\section{Conclusion}

The current study sought to characterize the nature of the two previously observed peaks observed in the frequency domain spectra for simple reaches. This was accomplished through the manipulations of online vision, accuracy-based instruction sets, and trial scheduling. It was hypothesized that if the peaks represented visual (i.e., the $\alpha_{\text {Peak }}$ ) and non-visual (i.e., $\beta_{\text {Peak }}$ ) online 
623 control processes voluntarily modifiable by instruction sets, then their relative contributions to

624 the trajectories should increase in the presence (i.e., the $\alpha_{\text {Peak }}$ ) and the absence (i.e., $\beta_{\text {Peak }}$ ) of

625 online vision, respectively. Additionally, high-accuracy instructions were predicted to further

626 facilitate the respective contributions in compatible sensory environments. In partial agreement

627 with these hypotheses, the relative magnitude of the $\alpha_{\text {Peak }}$ increased in the presence of online

628 visual information and also when participants were given high-accuracy instruction sets.

629 However, this instruction-based modulation was more robust when vision conditions were

630 blocked. In contrast, the results associated with the $\beta_{\text {Peak }}$ indicated that its relative magnitude

631 increased in the absence of online vision, but decreased with instructions to be accurate when

632 vision conditions were also randomized. Thus, unlike the $\alpha_{\text {Peak }}$, the magnitude of the $\beta_{\text {Peak }}$ does

633 not represent the direct contribution of an online control process, but rather, it likely represents

634 the suppression of proprioceptive spinal feedback loops, which may otherwise interfere with the

635 production of smooth and accurate movements. 
Accuracy instructions and online control

636

637

638

639

640

641

642

643

644

645

646

647

648

649

650

651

652

653 Craik, K. J. W. (1947). Theory of the human operator in control systems. I. The operator as an 654

\section{References}

Adam, J. J. (1992). The effects of objectives and constraints on motor control strategy in reciprocal aiming movements. Journal of Motor Behavior, 24(2), 173-185. doi:10.1080/00222895.1992.9941613

Bakeman, R. (2005). Recommended effect size statistics for repeated measures designs. Behavior Research Methods, 37, 379-384. doi: 10.3758/BF03192707

Bernier, P.-M., Chua, R., Franks, I. M., \& Khan, M. A. (2006). Determinants of offline processing of visual information for the control of reaching movements. Journal of Motor Behavior, 38(5), 331-338. doi:10.3200/JMBR.38.5.331-338

Binsted, G., Brownell, K., Vorontsova, Z., Heath, M., \& Saucier, D. (2007). Visuomotor system uses target features unavailable to conscious awareness. Proceedings of the National Academy of Sciences of the United States of America, 104(31), 12669-12672. doi:10.1073/pnas.0702307104

Cheng, D. T., Luis, M., \& Tremblay, L. (2008). Randomizing visual feedback in manual aiming: Reminiscence of the previous trial condition and prior knowledge of feedback availability. Experimental Brain Research, 189(4), 403-410. doi:10.1007/s00221-008$1436-3$ engineering system. British Journal of Psychology, 38, 56-61. 
Accuracy instructions and online control

655 Cressman, E. K., Cameron, B. D., Lam, M. Y., Franks, I. M., \& Chua, R. (2010). Movement 656

657 duration does not affect automatic online control. Human Movement Science, 29(6), 871-881. doi:10.1016/j.humov.2010.07.001

658

659

660

661

662

663

664

665

666

667

668

669

670

671 Elliott, D., Binsted, G., \& Heath, M. (1999). The control of goal-directed limb movements:

672

673 law. The Quarterly Journal of Experimental Psychology Section A : Human Experimental Psychology, 35A(2), 251-278. doi:10.1080/14640748308402133

de Grosbois (2017). The quantification of the online control of goal-directed movement using frequency domain analysis (Doctoral Dissertation). Retrieved from the Tspace dissertation repository. http://hdl.handle.net/1807/80730

de Grosbois, J., \& Tremblay, L. (2016). Quantifying online visuomotor feedback utilization in the frequency domain. Behavior Research Methods, 48(4), 1653-1666. doi:10.3758/s13428-015-0682-0

de Grosbois, J., \& Tremblay, L. (2017). Distinct and flexible rates of online control. Psychological Research. doi:10.1007/s00426-017-0888-0

de Grosbois, J., \& Tremblay, L. (2018). Which measures of online control are least sensitive to offline processes? Motor Control, 22(3), 358-376.

Correcting errors in the trajectory. Human Movement Science, 18(2-3), 121-136. doi:10.1016/S0167-9457(99)00004-4 
Accuracy instructions and online control

674 Elliott, D., Carson, R., Goodman, D., \& Chua, R. (1991). Discrete vs. continuous visual control

675

676

677

678

679

680

681

682

683

684

685

686

687

688

689

690

691

692

693

of manual aiming. Human Movement Science, 10, 393-418. doi:10.1016/01679457(91)90013-N

Elliott, D., Dutoy, C., Andrew, M., Burkitt, J. J., Grierson, L. E. M., Lyons, J. L., Hayes, S. J., \& Bennet, S. J. (2014). The influence of visual feedback and prior knowledge about visual feedback on vertical aiming strategies. Journal of Motor Behavior, 46(6), 433-443. doi:10.1080/00222895.2014.933767

Elliott, D., Hansen, S., Grierson, L. E. M., Lyons, J., Bennett, S. J., \& Hayes, S. J. (2010). Goaldirected aiming: Two components but multiple processes. Psychological Bulletin, 136(6), 1023-1044. doi:10.1037/a0020958

Elliott, D., Hansen, S., Mendoza, J., \& Tremblay, L. (2004). Learning to optimize speed, accuracy, and energy expenditure: A framework for understanding speed-accuracy relations in goal-directed aiming. Journal of Motor Behavior, 36(3), 339-351. doi:10.3200/JMBR.36.3.339-351

Elliott, D., Helsen, W. F., \& Chua, R. (2001). A century later: Woodworth's (1899) twocomponent model of goal-directed aiming. Psychological Bulletin, 127(3), 342-357. doi:10.1037//0033-2909.127.3.342

Elliott, D., Lyons, J., Hayes, S. J., Burkitt, J. J., Roberts, J. W., Grierson, L. E. M., ... Bennett, S. J. (2017). The multiple process model of goal-directed reaching revisited. Neuroscience and Biobehavioral Reviews, 72, 95-110. doi:10.1016/j.neubiorev.2016.11.016 
Accuracy instructions and online control

694 Faul, F., Erdfelder, E., Lang, A.-G., \& Buchner, A. (2007). G*Power 3: A flexible statistical

695

696

697

698

699

700

701

702

703

704

705

706

707

708

709

710

711

712 power analysis program for the social, behavioral, and biomedical sciences. Behavior Research Methods, 39, 175-191.

Fink, A. J. P., Croce, K. R., Huang, Z. J., Abbott, L. F., Thomas, M., Azim, E., ... Harbor, C. S. (2014). Presynaptic inhibition of spinal sensory feedback ensures smooth movement. Nature, 509(7498), 43-48. doi:10.1038/nature13276.Presynaptic

Fitts, P. (1954). The information capacity of the human motor system in controlling the amplitude of movement. Journal of Experimental Psychology, 47, 381-391. doi:10.1037/h0055392

Flash, T., \& Hogan, N. (1985). The coordination of arm movements: An experimentally confirmed mathematical model. The Journal of Neuroscience, 5(7), 1688-1703.

Goodman, R., Crainic, V., Wijeyaratnam, D. O., de Grosbois, J., Bested, S. R., \& Tremblay, L. (2018). Amending ongoing upper-limb reaches: Visual and proprioceptive contributions. Multisensory Research. 31(5), 455-480. doi:10.1163/22134808-00002615

Gosselin-Kessiby, N., Messier, J., \& Kalaska, J. F. (2008). Evidence for automatic online adjustments of hand orientation during natural reaching movements to stationary targets. Journal of Neurophysiology, 99, 1653-1671. doi::10.1152/jn.00980.2007

Hansen, S., Elliott, D., \& Khan, M. A. (2008). Quantifying the variability of three-dimensional aiming movements using ellipsoids. Motor Control, 12, 241-251. 
Accuracy instructions and online control

713 Hansen, S., Glazebrook, C. M., Anson, J. G., Weeks, D. J., \& Elliott, D. (2006). The influence of and execution. Canadian Journal of Experimental Psychology, 60(3), 200-208.

716 doi:10.1037/cjep2006019

717

718

719

720

721

722

723

724

725

726

727

728

729

730

731 advance information about target location and visual feedback on movement planning

Heath, M. (2005). Role of limb and target vision in the online control of memory-guided reaches. Motor Control, 9(3), 281-311.

Heath, M., Westwood, D. A., \& Binsted, G. (2004). The Control of Memory-Guided Reaching Movements in Peripersonal Space. Motor Control, 8, 76-106.

Howarth, C. I., Beggs, W. D. A., \& Bowden, J. (1971). The relationship between speed and accuracy of movement aimed at a target. Acta Psychologica, 35, 207-218. doi:10.1016/0001-6918(71)90022-9

Jeannerod, M. (1986). Are corrections in accurate arm movements corrective? In H. J. Freund, U. Buttner, B. Cohen, \& J. Noth (Eds.), Progress in Brain Research: The oculomotor and skeletal motor systems: Differences and similarities (pp. 353-360). Amsterdam: Elsevier Science Publishers.

Keele, S. W., \& Posner, M. I. (1968). Processing of visual feedback in rapid aiming movements. Journal of Experimental Psychology, 77(1), 155-158. doi:10.1037/h0025754

Kennedy, A., Bhattacharjee, A., Hansen, S., Reid, C., \& Tremblay, L. (2015). Online vision as a function of real-time limb velocity: Another case for optimal windows. Journal of 
733
Khan, M. A, \& Franks, I. M. (2003). Online versus offline processing of visual feedback in the production of component submovements. Journal of Motor Behavior, 35(3), 285-295. doi:10.1080/00222890309602141

Khan, M. A., Chua, R., Elliott, D., Coull, J., \& Lyons, J. (2002). Optimal control strategies under different feedback schedules: Kinematic evidence. Journal of Motor Behavior, 34(1), 45-57. doi:10.1080/00222890209601930

Khan, M. A., Franks, I. M., \& Goodman, D. (1998). The effect of practice on the control of rapid aiming movements : Evidence for an interdependency between programming and feedback processing. The Quarterly Journal of Experimental Psychology Section A : Human Experimental Psychology, 51A(2), 425-444. doi:10.1080/713755756

Khan, M. A., Franks, I. M., Elliott, D., Lawrence, G. P., Chua, R., Bernier, P.-M., ... Weeks, D. J. (2006). Inferring online and offline processing of visual feedback in target-directed movements from kinematic data. Neuroscience and Biobehavioral Reviews, 30, 11061121. doi:10.1016/j.neubiorev.2006.05.002

Khan, M. A., Lawrence, G. P., Franks, I. M., \& Buckolz, E. (2004). The utilization of visual feedback from peripheral and central vision in the control of direction. Experimental Brain Research, 158, 241-251. doi:10.1007/s00221-004-1897-y

Lawrence, M. A. (2013). ez: Easy analysis and visualization of factorial experiments. R package 
Accuracy instructions and online control

version 4.2-2. http://CRAN.R-project.org/package=ez

752 Liu, D., \& Todorov, E. (2007). Evidence for the flexible sensorimotor strategies predicted by

753

754

755

756

757

758

759

760

761

762

763

764

765

766

767

768

769 optimal feedback conrol. Journal of Neuroscience, 27(35), 9354-9368.

doi:10.1523/JNEUROSCI.1110-06.2007

Loftus, G. R., \& Masson, M. E. (1994). Using confidence intervals in within-subject designs. Psychonomic Bulletin \& Review, 1(4), 476-490. doi:10.3758/BF03210951

Messier, J., \& Kalaska, J. F. (1999). Comparison of variability of initial kinematics and endpoints of reaching movements. Experimental Brain Research, 125(2), 139-52. doi:10.1007/s002210050669

Meyer, D. E., Abrams, R. A., Kornblum, S., Wright, C. E., \& Smith, J. E. (1988). Optimality in human motor performance: Ideal control of rapid aimed movements. Psychological Review, 95(3), 340-70. doi:10.1037/0033-295X.95.3.340

Milgram, P. (1987). A spectacle-mounted liquid-crystal tachistoscope. Behavior Research Methods, Instruments, \& Computers, 19(5), 449-456. doi:10.3758/BF03205613

Mutha, P. K., Boulinguez, P., \& Sainburg, R. L. (2008). Visual modulation of proprioceptive reflexes during movement. Brain Research, 1246, 54-69.

doi:10.1016/j.brainres.2008.09.061

Noy, L., Alon, U., \& Friedman, J. (2015). Corrective jitter motion shows similar individual frequencies for the arm and the finger. Experimental Brain Research, 233(4), 1307- 
771

772

773

774

775

776

777

778

Olejnik, S., \& Algina, J. (2003). Generalized eta and omega squared statistics: Measures of effect size for some common research designs. Psychological Methods, 8, 434-447. doi:10.1037/1082-989X.8.4.434

Oldfield, R. C. (1971). The assessment and analysis of handedness: The Edinburgh inventory. Neuropsychologia 9, 97-113. doi:10.1016/0028-3932(71) 90067-4

Pélisson, D., Prablanc, C., Goodale, A., \& Jeannerod, M. (1986). Visual control of reaching movements without vision of the limb: II. Evidence of fast unconscious processes correcting the trajectory of the hand to the final position of a double-step stimulus. Experimental Brain Research, 62, 303-311. doi:10.1007/BF00238849

Plamondon, R., \& Alimi, A. M. (1997). Speed/accuracy trade-offs in target-directed movements. Behavioral and Brain Sciences, 20, 279-303. doi:10.1017/S0140525X97001441

Poston, B., van Gemmert, A. W. A., Sharma, S., Chakrabarti, S., Zavaremi, S. H., \& Stelmach, G. (2013). Movement trajectory smoothness is not associated with the endpoint accuracy of rapid multi-joint arm movements in young and older adults. Acta Psychologica, 143(2), 157-167. doi:10.1016/j.actpsy.2013.02.011

R Development Core Team (2014). R: A language and environment for statistical computing. Vienna, Austria: R Foundation for Statistical Computing. Retrieved from www.Rproject.org/

Randall, R. B. (2008). Spectral analysis and correlation. In D. Havelock, S. Kuwano, \& M. Vorlander (Eds.), Handbook of signal processing in acoustics (pp. 33-52). New York: 
Accuracy instructions and online control

791 Springer

792 Roberts, J. W., Burkitt, J. J., Elliott, D., \& Lyons, J. L. (2016). The impact of strategic trajectory 793 optimization on illu sory target biases during goal-directed aiming. Journal of Motor

794 Behavior, 48(6), 542-551. doi:10.1080/00222895.2016.1161588

795 Saunders, J. A., \& Knill, D. C. (2003). Humans use continuous visual feedback from the hand to 796 797 control fast reaching movements. Experimental Brain Research, 152(3), 341-352. doi:10.1007/s00221-003-1525-2

798

799

800

801

802

803

804

805

806

807

808

809

Soechting, J. F. (1984). Effect of target size on spatial and temporal characteristics of a pointing movement in man. Experimental Brain Research, 54, 121-132. doi:10.1007/BF00235824

Tremblay, L., Hansen, S., Kennedy, A., \& Cheng, D. T. (2013). The utility of vision during action: Multiple visuomotor processes? Journal of Motor Behavior, 45(2), 91-99. doi:10.1080/00222895.2012.747483

Tresilian, J.R., Stelmach, G.E., \& Adler, C.H. (1997). Stability of reach-to-grasp movement patterns in Parkinson's disease. Brain, 120, 2093-2111. doi:10.1093/brain/120.11.2093

Veyrat-Masson, M., Brière, J., \& Proteau, L. (2010). Automaticity of online control processes in manual aiming. Journal of Vision, 10(14)(27), 1-14. doi:10.1167/10.14.27

Warner, R. M. (1998). Spectral analysis of time series data. New York: Guilford Press.

Woodworth, R. S. (1899). The accuracy of voluntary movement. Psychological Review, 3(2), 1 - 
811 Zelaznik, H. N., Hawkins, B., \& Kisselburgh, L. (1983). Rapid visual feedback processing in 812 single-aiming movements. Journal of Motor Behavior, 15(3), 217-236. doi:10.1080/00222895.1983.10735298

814 Zhai, S., Kong, J., \& Ren, X. (2004). Speed-accuracy tradeoff in Fitts' law tasks - on the 815 equivalency of actual and nominal pointing precision. International Journal of HumanComputer Studies, 61(6), 823-856. doi:10.1016/j.ijhcs.2004.09.007 
817 Table 1. Means and standard deviations (in parentheses) for all dependent variables across

818 experimental manipulations of trial scheduling (i.e., blocked \& random), accuracy instruction set 819 (i.e., low \& high), and vision condition (i.e., full-vision and no-vision).

\begin{tabular}{|c|c|c|c|c|c|c|c|c|}
\hline & \multicolumn{4}{|c|}{ Experiment 1 (Blocked Vision) } & \multicolumn{4}{|c|}{ Experiment 2 (Randomized Vision) } \\
\hline & \multicolumn{2}{|c|}{ Low Accuracy } & \multicolumn{2}{|c|}{ High Accuracy } & \multicolumn{2}{|c|}{ Low Accuracy } & \multicolumn{2}{|c|}{ High Accuracy } \\
\hline & $\begin{array}{l}\text { Full- } \\
\text { Vision }\end{array}$ & $\begin{array}{c}\text { No- } \\
\text { Vision }\end{array}$ & $\begin{array}{l}\text { Full- } \\
\text { Vision }\end{array}$ & $\begin{array}{c}\text { No- } \\
\text { Vision }\end{array}$ & $\begin{array}{l}\text { Full- } \\
\text { Vision }\end{array}$ & $\begin{array}{c}\text { No- } \\
\text { Vision }\end{array}$ & $\begin{array}{l}\text { Full- } \\
\text { Vision }\end{array}$ & $\begin{array}{c}\text { No- } \\
\text { Vision }\end{array}$ \\
\hline $\begin{array}{l}\text { Endpoint } \\
(\mathrm{mm})\end{array}$ & $\begin{array}{l}310.3 \\
(4.3)\end{array}$ & $\begin{array}{l}306.9 \\
(11.3)\end{array}$ & $\begin{array}{c}309.6 \\
(3.9)\end{array}$ & $\begin{array}{l}304.3 \\
(12.7)\end{array}$ & $\begin{array}{l}310.5 \\
(3.3)\end{array}$ & $\begin{array}{c}304.4 \\
(8.9)\end{array}$ & $\begin{array}{c}309.3 \\
(3.0)\end{array}$ & $\begin{array}{c}302.3 \\
(6.6)\end{array}$ \\
\hline $\begin{array}{l}\text { Variable } \\
\text { Error }(\mathrm{mm})\end{array}$ & $5.1(1.3)$ & $9.3(2.9)$ & $4.3(0.9)$ & $7.8(2.0)$ & $5.3(2.8)$ & $7.2(1.9)$ & $3.9(1.3)$ & $6.5(1.1)$ \\
\hline TAPV (ms) & $284(18)$ & $288(23)$ & $290(21)$ & $291(26)$ & $290(18)$ & $285(16)$ & $298(15)$ & $287(15)$ \\
\hline $\mathrm{Z}^{2}$ & $\begin{array}{c}0.29 \\
(0.24)\end{array}$ & $\begin{array}{c}1.22 \\
(0.84)\end{array}$ & $\begin{array}{c}0.29 \\
(0.18)\end{array}$ & $\begin{array}{c}1.08 \\
(0.41)\end{array}$ & $\begin{array}{c}0.52 \\
(0.60)\end{array}$ & $\begin{array}{c}0.96 \\
(0.65)\end{array}$ & $\begin{array}{c}0.25 \\
(0.26)\end{array}$ & $\begin{array}{c}0.81 \\
(0.32)\end{array}$ \\
\hline $\begin{array}{l}\alpha_{\text {Peak }} \\
\text { Frequency } \\
(\mathrm{Hz})\end{array}$ & $7.1(0.8)$ & $7.2(0.8)$ & $7.4(1.0)$ & $6.9(0.6)$ & $6.8(0.6)$ & $6.8(0.7)$ & $7.1(0.7)$ & $6.9(0.6)$ \\
\hline $\begin{array}{l}\alpha_{\text {Peak }} \\
\text { Magnitude } \\
(\%)\end{array}$ & $\begin{array}{l}25.0 \\
(2.9)\end{array}$ & $\begin{array}{l}19.8 \\
(5.2)\end{array}$ & $\begin{array}{l}25.7 \\
(5.0)\end{array}$ & $\begin{array}{l}21.6 \\
(4.3)\end{array}$ & $\begin{array}{l}31.0 \\
(3.4)\end{array}$ & $\begin{array}{l}27.6 \\
(3.3)\end{array}$ & $\begin{array}{l}32.6 \\
(3.5)\end{array}$ & $\begin{array}{l}29.2 \\
(3.2)\end{array}$ \\
\hline $\begin{array}{l}\beta_{\text {Peak }} \\
\text { Frequency } \\
(\mathrm{Hz})\end{array}$ & $(-)$ & $\begin{array}{l}18.2 \\
(0.8)\end{array}$ & $(-)$ & $\begin{array}{l}18.4 \\
(0.9)\end{array}$ & $(-)$ & $\begin{array}{l}17.8 \\
(0.8)\end{array}$ & $(-)$ & $\begin{array}{l}17.7 \\
(1.3)\end{array}$ \\
\hline $\begin{array}{l}\beta_{\text {Peak }} \\
\text { Magnitude } \\
(\%)\end{array}$ & $2.3(1.0)$ & $4.9(1.5)$ & $2.2(1.2)$ & $4.7(1.1)$ & $1.8(0.6)$ & $3.9(1.1)$ & $1.1(0.3)$ & $3.3(0.9)$ \\
\hline
\end{tabular}




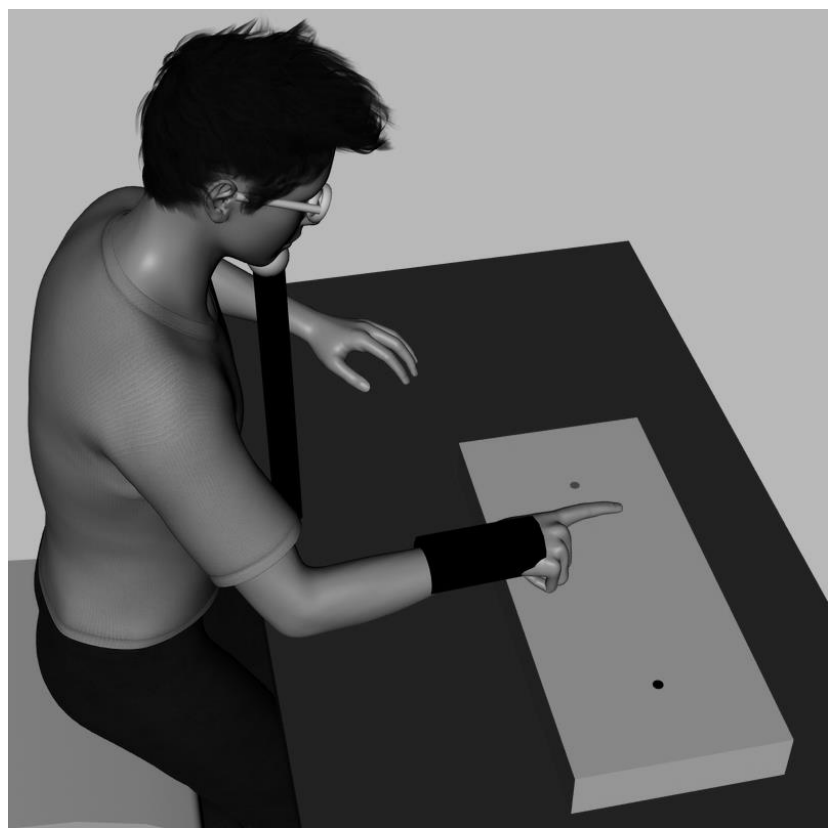

820 Figure 1. A depiction of the experimental setup (Note. Not to scale). 

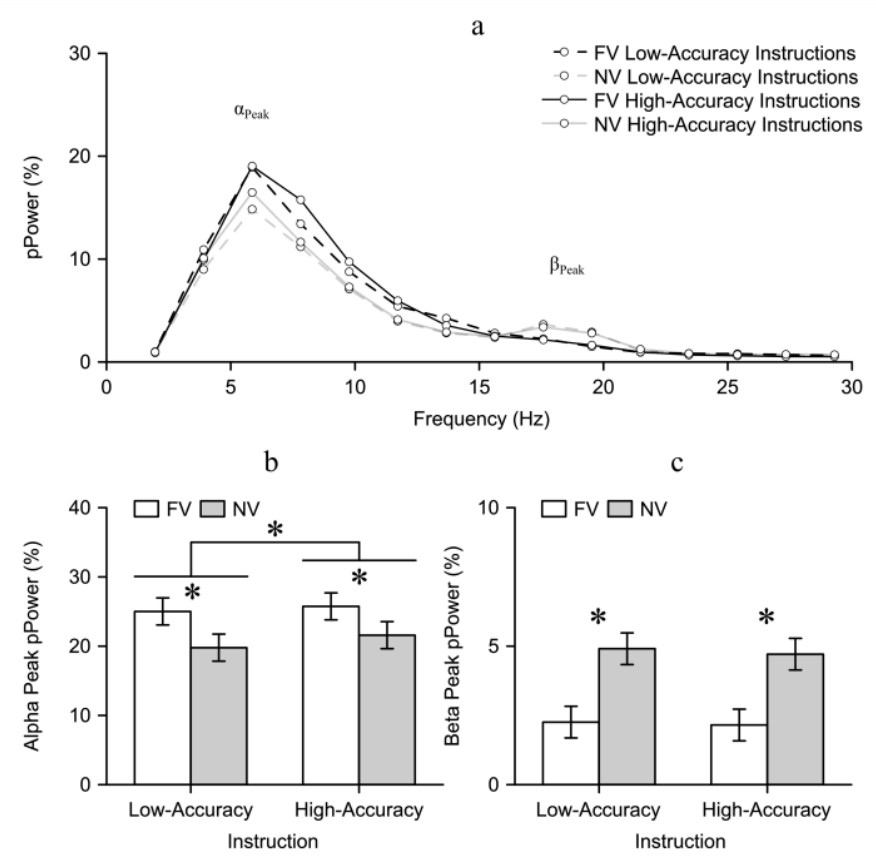

821 Figure 2. The main findings of Experiment 1: a) The mean pPower spectra of the four

822 conditions; b) The relative magnitude of the $\alpha_{\text {Peak }}$; and c) the relative magnitude of the $\beta_{\text {Peak }}$

823 across experimental conditions. * indicates $p<.05$. Error bars represent within-subject $95 \%$

824 confidence intervals. 

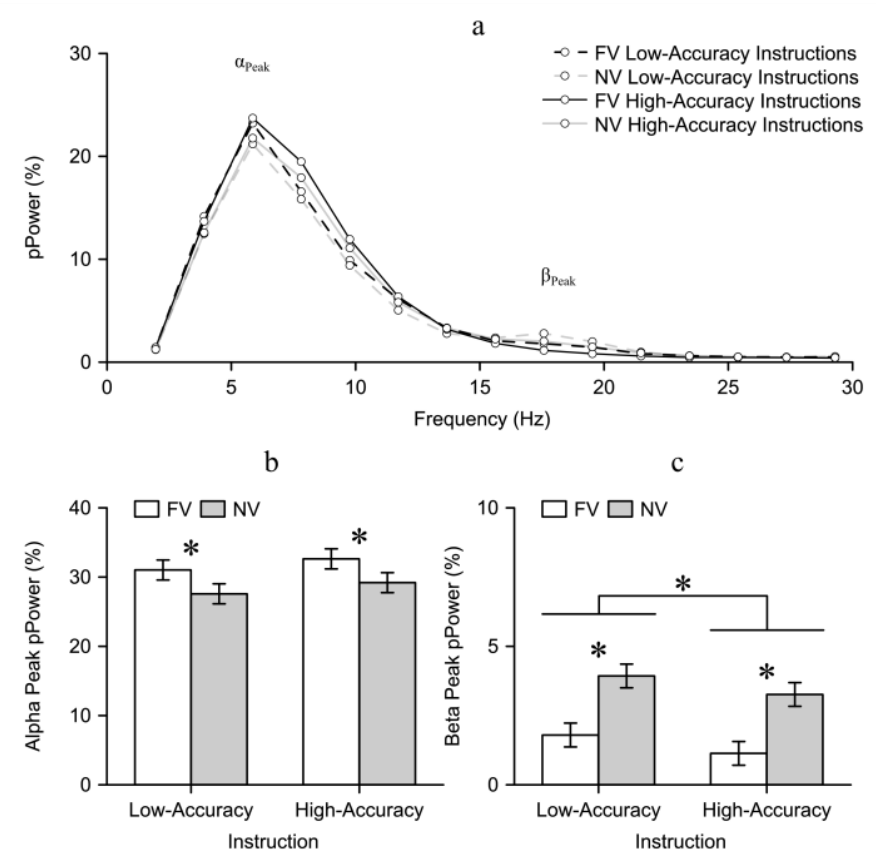

825 Figure 3. The main findings of Experiment 2: a) The mean pPower spectra of the four

826 conditions; b) The relative magnitude of the $\alpha_{\text {Peak }}$; and c) the relative magnitude of the $\beta_{\text {Peak }}$

827 across experimental conditions. * indicates $p<.05$. Error bars represent within-subject $95 \%$

828 confidence intervals. 